\title{
Antiplatelet Therapy After Percutaneous Coronary Intervention - Past, Current and Future Perspectives -
}

\author{
Masahiro Natsuaki, MD; Takeshi Kimura, MD
}

Optimal antiplatelet therapy after percutaneous coronary intervention $(\mathrm{PCI})$ has been changed in parallel with the improvements of coronary stent and antiplatelet therapy. Over the past 25 years, dual antiplatelet therapy (DAPT) with aspirin plus P2Y 12 inhibitor has been the standard of care used after coronary stent implantation. First-generation drug-eluting stent (DES) appeared to increase the risk of late stent thrombosis, and duration of DAPT was prolonged to 12 months. DAPT duration up to 12 months was the dominant strategy after DES implantation in the subsequent $>10$ years, although there was no dedicated randomized controlled trial supporting this recommendation. The current recommendation of DAPT duration is getting shorter due to the development of new-generation $\mathrm{DES}$, use of a P2Y 12 inhibitor as a monotherapy, and the increasing prevalence of high-bleeding risk patients. Furthermore, an aspirin-free strategy is now emerging as one of the novel strategies of antiplatelet therapy after PCl. This review gives an overview of the history of antiplatelet therapy and provides current and future perspectives on antiplatelet therapy after PCl.

Key Words: Antiplatelet therapy; Coronary artery disease; Percutaneous coronary intervention (PCI)

\section{Inception of Dual Antiplatelet Therapy}

In 1995, 2 seminal studies presented by Colombo A, and Van Belle E, respectively, suggested the combination of aspirin and ticlopidine as a safe replacement for anticoagulant therapy after coronary stent implantation. ${ }^{\mathbf{1 2}}$ In 1996, the ISAR (Intracoronary Stenting and Antithrombotic Regimen) trial demonstrated that dual antiplatelet therapy (DAPT) with ticlopidine plus aspirin, as compared with conventional anticoagulant therapy, significantly reduced the 30-day incidence of both cardiac events and hemorrhagic/vascular complications after bare-metal stent (BMS) implantation (Figure 1). ${ }^{3}$ In 1998, aspirin and ticlopidine treatment also demonstrated a resultant lower rate of stent thrombosis at 1-month after BMS implantation as compared with aspirin alone and a combination of aspirin and warfarin in the STARS (Stent Anticoagulation Restenosis Study) trial. ${ }^{4}$ FANTASTIC (Full Anticoagulation Versus Aspirin and Ticlopidine) also showed that DAPT with aspirin and ticlopidine significantly reduced rates of bleeding and subacute stent occlusion compared with conventional anticoagulation..$^{5}$ In the MATTIS (Multicentre Aspirin and Ticlopidine Trial after Intracoronary Stenting) study, high-risk patients receiving DAPT after coronary stenting had significantly reduced bleeding and vascular complications as compared with when they were treated with aspirin and anticoagulation. ${ }^{6}$ Since then, DAPT with aspirin plus thienopyridine has been the standard of care used after coronary stent implantation.

Clopidogrel emerged as a new $\mathrm{P}_{2} \mathrm{Y}_{12}$ inhibitor in place of ticlopidine; it had greater molar potency and a better safety profile than ticlopidine. In 1997, clopidogrel was approved by the U.S. Food and Drug Administration (FDA). In 2000, the CLASSICS (Clopidogrel Aspirin Stent International Cooperative Study) trial showed that the safety/ tolerability of clopidogrel was superior to that of ticlopidine, with comparable efficacy with regard to cardiac event treatment after successful stenting. ${ }^{7}$

\section{First Generation DES and Long DAPT}

In 2001, DAPT with clopidogrel plus aspirin for 3-12 months in patients with acute coronary syndrome (ACS) without ST-segment elevation showed significant risk reduction for cardiovascular events as compared to aspirin alone in the CURE (Clopidogrel in Unstable angina to prevent Recurrent Events) trial. ${ }^{8}$ Long-term administration of clopidogrel on top of aspirin after percutaneous coronary intervention (PCI) in ACS patients was also associated with a lower rate of cardiovascular events as compared to aspirin alone in the PC-CURE trial. ${ }^{9}$

In 2002, long-term (1-year) clopidogrel therapy signifi-

Received August 26, 2021; accepted August 26, 2021; J-STAGE Advance Publication released online September 23, 2021

Department of Cardiovascular Medicine, Saga University Hospital, Saga (M.N.); Department of Cardiovascular Medicine, Graduate School of Medicine, Kyoto University, Kyoto (T.K.), Japan

Mailing address: Takeshi Kimura, MD, Department of Cardiovascular Medicine, Graduate School of Medicine, Kyoto University, 54 Shogoin Kawahara-cho, Sakyo-ku, Kyoto 606-8507, Japan. E-mail: taketaka@kuhp.kyoto-u.ac.jp

All rights are reserved to the Japanese Circulation Society. For permissions, please e-mail: cj@j-circ.or.jp

ISSN-1346-9843 
Ticlopidine or Clopidogrel Trials

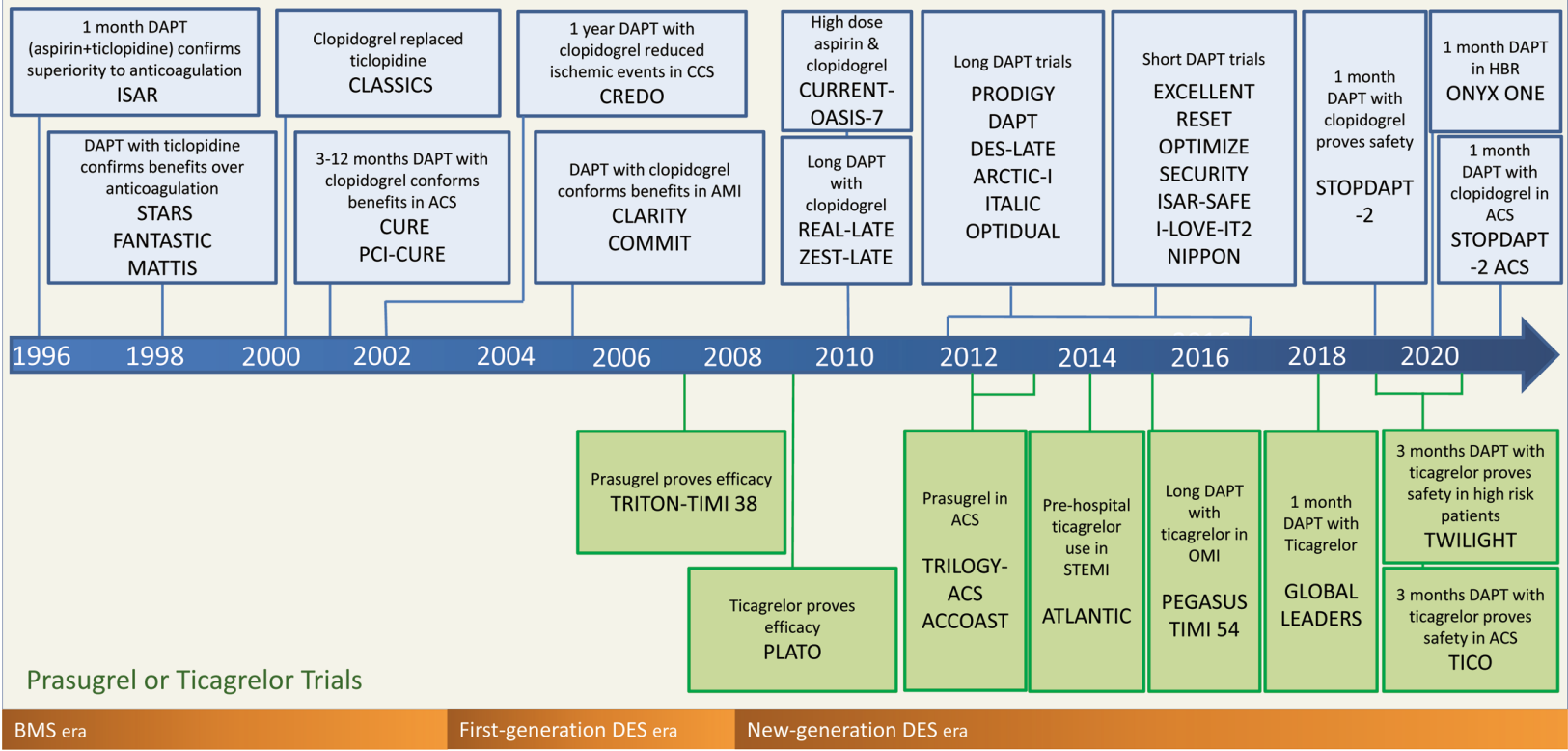

Figure 1. History of DAPT trials for patients undergoing PCI. ACS, acute coronary syndrome; AMI, acute myocardial infarction; CCS, chronic coronary syndrome; DAPT, dual-antiplatelet therapy; HBR, high bleeding risk; OMI, old myocardial infarction; STEMI, ST-elevation myocardial infarction.

cantly reduced the risk of adverse ischemic events (the combined risk of death, myocardial infarction, or stroke) in patients who were to undergo elective PCI in the CREDO trial. ${ }^{10}$

In 2003, a first-generation drug-eluting stent (DES), the sirolimus-eluting stent, was approved by the FDA. A firstgeneration DES resolved the problems of restenosis and repeated target-lesion revascularization (TLR) after PCI, which had been the main concerns after BMS implantation." However, late adverse events such as very late stent thrombosis or late TLR beyond 1 year have emerged as new problems after first-generation DES implantation. ${ }^{\mathbf{1 2}}$ Inflammatory reaction, hypersensitivity, endothelial dysfunction, and neoatherosclerosis were accused as the pathophysiologic mechanisms for late adverse events. In 2006, an expert FDA panel concluded that first-generation DES appeared to increase the risk of late stent thrombosis and recommended that the duration of DAPT should be prolonged to 12 months. There was no dedicated randomized controlled trial supporting this recommendation. ${ }^{13}$ Nevertheless, DAPT duration up to 12 months was the dominant strategy after DES implantation in the following $>10$ years. Based on previous findings from the PCI-CURE, CREDO trial, and observational studies suggesting persistent risk of stent thrombosis beyond 6 months after stent implantion, ${ }^{9,10,14-16}$ the 2011 American Heart Association (AHA) guideline recommended a minimum DAPT duration of at least 12 months after first-generation DES implantation. ${ }^{17}$ The European Society of Cardiology (ESC) guidelines in 2010 recommended 1 month of DAPT after BMS in stable patients, 6-12 months of DAPT after DES, and 12 months of DAPT in the case of ACS. ${ }^{18}$

\section{Introduction of a New Generation P2Y 12 Inhibitor}

In 2007, a novel P2 $Y_{12}$ inhibitor, prasugrel, as compared to clopidogrel, was evaluated in TRITON-TIMI (Trial to Assess Improvement in Therapeutic Outcomes by Optimizing Platelet Inhibition with Prasugrel-Thrombolysis in Myocardial Infarction) $38 .{ }^{19}$ In patients with ACS, prasugrel was associated with significantly reduced rates of ischemic events, including stent thrombosis, but with an increased risk of major bleeding, including fatal bleeding. Overall, mortality did not differ significantly between the treatment groups. In 2009, another novel P2 Y 12 inhibitor, ticagrelor, as compared to clopidogrel, was evaluated in PLATO (Platelet Inhibition and Patient Outcomes). ${ }^{20}$ In ACS patients with or without ST-segment elevation, treatment with ticagrelor, as compared to clopidogrel, significantly reduced the rate of death from vascular causes, myocardial infarction, or stroke without an increase in the rate of overall major bleeding, but with an increase in the rate of non-coronary artery bypass grafting (CABG)-related bleeding. In 2011, AHA guidelines stated that patients receiving a stent (BMS or DES) during PCI for ACS were recommended to use a $\mathrm{P}_{2} \mathrm{Y}_{12}$ inhibitor with clopidogrel $75 \mathrm{mg}$ daily, prasugrel $10 \mathrm{mg}$ daily, or ticagrelor $90 \mathrm{mg}$ twice daily for at least 12 months. ${ }^{17}$

\section{New Generation DES and Short Duration of DAPT}

In 2008, a new-generation DES, an everolimus-eluting stent, was approved by the FDA. New-generation DESs were developed to overcome adverse events, especially very late stent thrombosis, related to the first-generation DES. The risk of stent thrombosis was significantly lower after implan- 


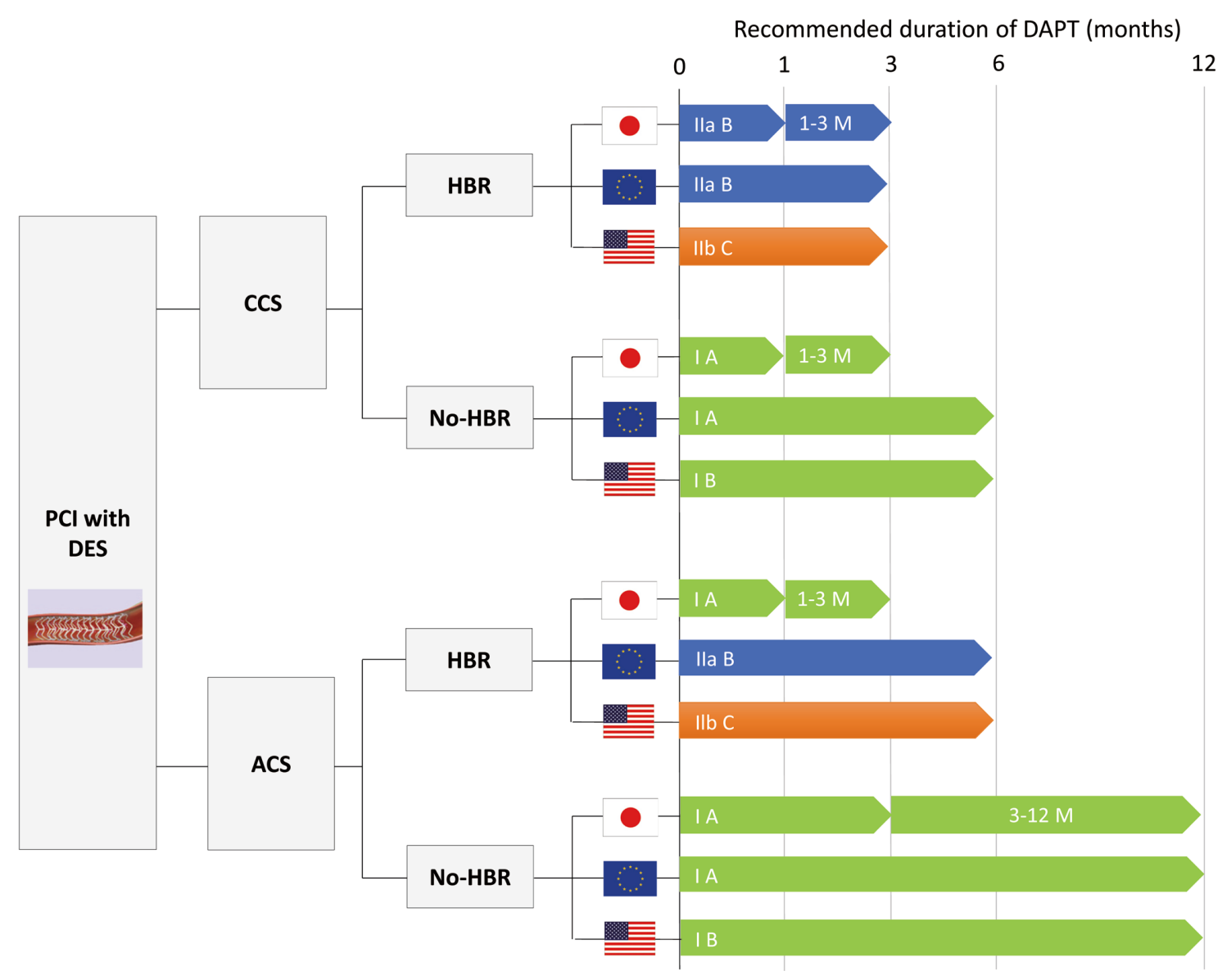

Figure 2. Guideline recommendations for DAPT in patients undergoing PCI. ACS, acute coronary syndrome; CCS, chronic coronary syndrome; DAPT, dual-antiplatelet therapy; DES, drug-eluting stent; $\mathrm{HBR}$, high bleeding risk; PCl, percutaneous coronary intervention.

tation of a new-generation DES as compared to a firstgeneration DES or BMS. ${ }^{21}$ Several randomized trials were conducted evaluating the short- and long-term DAPT to elucidate the appropriate DAPT duration after stent implantation, which included new-generation DESs. ${ }^{22-34}$ In the DAPT trial, prolonged DAPT beyond 1 year after placement of DESs, as compared to aspirin therapy alone, significantly reduced the risks of stent thrombosis and major adverse cardiovascular and cerebrovascular events, but was associated with an increased risk of bleeding. ${ }^{23}$ In contrast, several meta-analyses did not find any increased risk of stent thrombosis with a shorter duration of DAPT ${ }^{35-37}$ In addition, a shorter duration of DAPT resulted in fewer bleeding complications. ${ }^{35-37}$ Furthermore, there was a trend toward an excess mortality risk of prolonged DAPT duration relative to short-DAPT duration. ${ }^{38} \mathrm{~A}$ shorter duration of DAPT was considered to be appropriate for patients treated with newer-generation DESs, which are associated with lower stent thrombosis and myocardial infarction rates compared to that for patients treated with first-generation DESs. A focused update on DAPT from the AHA shortened the DAPT duration for patients with stable coronary artery disease (CAD) from 12 months to 6 months after new-generation DES implantation in

\section{6 (Figure 2). ${ }^{39}$}

\section{HBR and Short Duration of DAPT}

Prolonged DAPT with aspirin plus a $\mathrm{P}_{2} \mathrm{Y}_{12}$ inhibitor prevents ischemic events after coronary stenting, but increases bleeding. ${ }^{23}$ Therefore, patients at high risk for bleeding who undergo PCI often received a BMS followed by 1 month of DAPT. In 2015, the LEADERS FREE (Prospective Randomized Comparison of the BioFreedom Biolimus A9 Drug-Coated Stent versus the Gazelle Bare-Metal Stent in Patients at High Bleeding Risk) trial revealed that a polymerfree biolimus-coated stent was superior to a BMS with respect to the primary safety endpoint of a composite of cardiac death, myocardial infarction, or stent thrombosis, and an efficacy endpoint of clinically driven target-lesion revascularization when used with a 1-month course of DAPT in patents with high bleeding risks (HBR). ${ }^{40}$ In 2017, the PRECISE-DAPT (Predicting Bleeding Complications in Patients Undergoing Stent Implantation and Subsequent Dual Antiplatelet Therapy) score was developed using a simple 5-item risk score, which provides a standardized tool for the prediction of out-of-hospital bleeding during DAPT. ${ }^{41}$ The 2017 ECS guidelines have 
Table. Clinical Studies Evaluating P2Y ${ }_{12}$ Receptor Inhibitor Monotherapy vs. DAPT After PCI

\begin{tabular}{|c|c|c|c|c|c|c|c|}
\hline Trials & $\begin{array}{l}\text { Number of } \\
\text { patients }\end{array}$ & $\begin{array}{c}\text { Target } \\
\text { patients }\end{array}$ & $\begin{array}{c}\text { DAPT } \\
\text { duration }\end{array}$ & $\mathbf{P}^{2} \mathbf{Y}_{12} \mathbf{i}$ & $\begin{array}{l}\text { Primary } \\
\text { endpoint }\end{array}$ & $\begin{array}{c}\text { Trial } \\
\text { design }\end{array}$ & Result \\
\hline GLOBAL LEADERS ${ }^{55}$ & 15,968 & $\mathrm{PCl}$ & 1 vs. 12 & Ticagrelor & Death/MI & Superiority & Not confirmed \\
\hline STOPDAPT-250 & 3,045 & $\mathrm{PCl}$ & 1 vs. 12 & Clopidogrel & NACE & Non-inferiority & Confirmed \\
\hline SMART-CHOICE 49 & 2,993 & $\mathrm{PCl}$ & 3 vs. 12 & Clopidogrel & NACE & Non-inferiority & Confirmed \\
\hline TWILIGHT51 & 9,006 & HTR/HBR & 3 vs. 12 & Ticagrelor & Bleeding & Superiority & Confirmed \\
\hline $\mathrm{TICO}^{54}$ & 3,056 & ACS & 3 vs. 12 & Ticagrelor & NACE & Superiority & Confirmed \\
\hline STOPDAPT-2 ACS59 & 4,136 & ACS & 1 vs. 12 & Clopidogrel & NACE & Non-inferiority & Not confirmed \\
\hline
\end{tabular}

ACS, acute coronary syndrome; DAPT, dual antiplatelet therapy; HBR, high bleeding risk; HTR, high thrombotic risk; MI, myocardial infarction; NACE, net adverse clinical event; PCl, percutaneous coronary intervention; $\mathrm{P}_{2} \mathrm{Y}_{12} \mathrm{i}, \mathrm{P}_{2} \mathrm{Y}_{12}$ inhibitor.

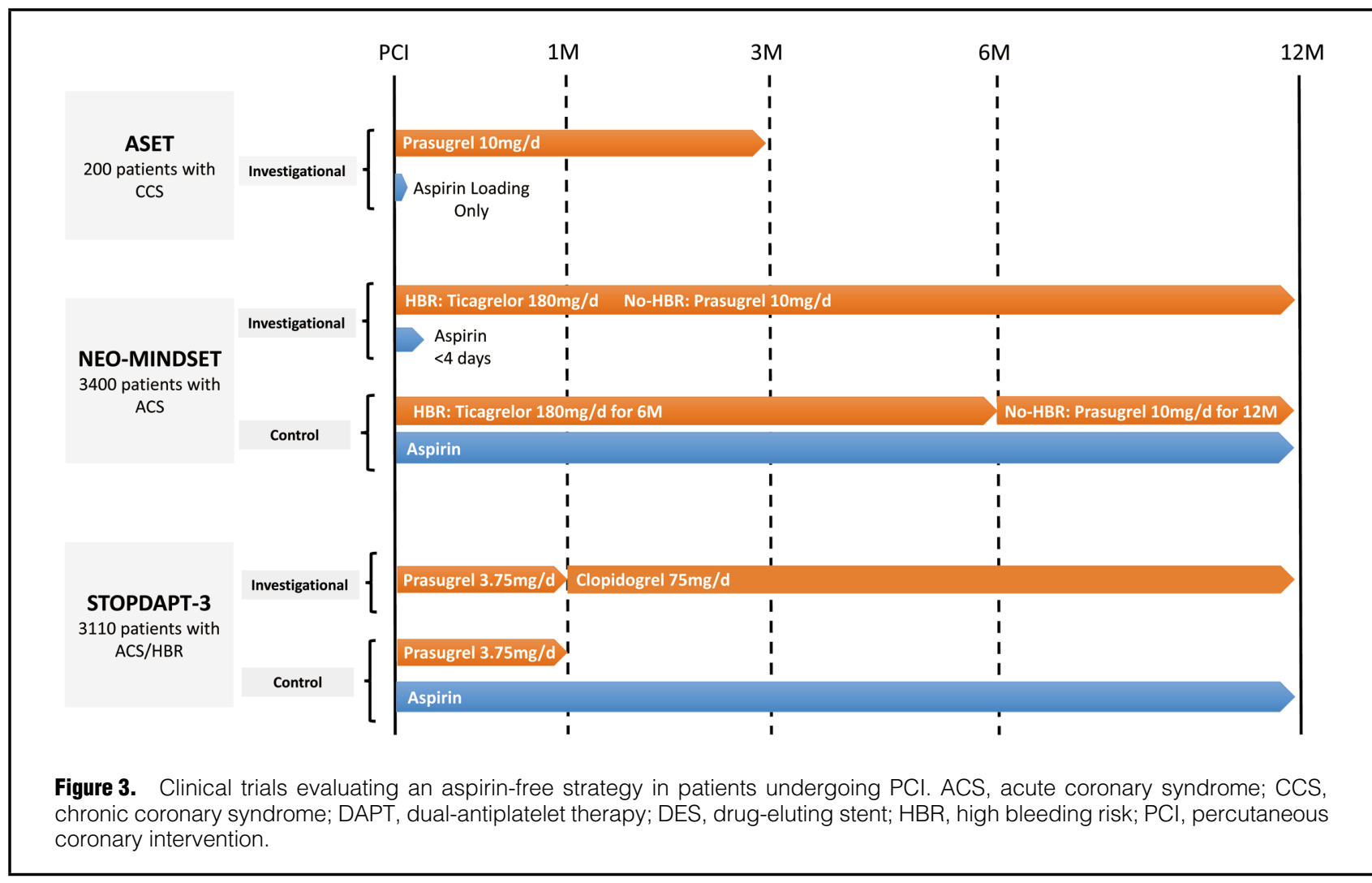

recommended to shorten the DAPT duration up to 3 months to minimize the bleeding complications in stable CAD patients with HBR (Class IIa). ${ }^{42}$ The CREDO-Kyoto thrombotic and bleeding risk scores were also developed to stratify the risks in Japanese patients undergoing PCI in 2018.43 The CREDO-Kyoto thrombotic and bleeding risk scores demonstrated modest accuracy in stratifying thrombotic and bleeding risks; however, a large proportion of patients at high thrombotic risk also had HBR.

The Academic Research Consortium for HBR (ARCHBR) has been proposed to standardize the definition of HBR from the literature review and by the consensus of experts in $2019 .{ }^{44}$ In the ARC-HBR initiative, HBR was arbitrarily defined as a Bleeding Academic Research Consortium (BARC) 3 or 5 bleeding $\geq 4 \%$ at 1 year or a risk of an intracranial hemorrhage $\geq 1 \%$ at 1 year. The Japanese version of the HBR (J-HBR) criteria have been proposed by consensus of the group working on the guidelines from the Japanese Circulation Society (JCS), which included factors such as low body weight, frailty, heart failure, and peripheral vascular disease on top of the factors included in the ARC-HBR criteria. ${ }^{45}$ Patients meeting J-HBR criteria are recommended to receive 1-3 months of DAPT after PCI regardless of the risk for thrombotic events, as advised in the JCS 2020 focused update guideline (Figure 2). ${ }^{45}$

In 2020, the ONYX ONE (A Randomized Controlled Trial With Resolute Onyx in One Month Dual Antiplatelet Therapy (DAPT) for High-Bleeding Risk Patients) trial revealed that use of polymer-based zotarolimus-eluting stents was non-inferior to use of polymer-free drug-coated stents with regard to safety and effectiveness composite outcomes among patients with HBR who received 1 month of DAPT after PCI. ${ }^{46}$ 


\section{P2Y 12 Inhibitor Monotherapy After a Very Short Duration of DAPT}

Aspirin has been the gold standard of single antiplatelet therapy (SAPT) after PCI. However, aspirin acting via the cyclooxygenase inhibition is associated with a higher risk for gastrointestinal bleeding as compared with a P2Y 12 inhibitor. ${ }^{47}$ Furthermore, in a meta-analysis, $\mathrm{P} 2 \mathrm{Y}_{12}$ inhibitor monotherapy was reported to be associated with a risk reduction for myocardial infarction as compared with aspirin monotherapy in the setting of secondary prevention. ${ }^{48}$ Considering the balance between ischemic and bleeding risks after PCI, P2Y12 inhibitor monotherapy is becoming the dominant strategy for SAPT after a short duration of DAPT in clinical trials (Table). In the SMARTCHOICE (Comparison Between P2Y12 Antagonist Monotherapy vs Dual Antiplatelet Therapy in Patients Undergoing Implantation of Coronary Drug-Eluting Stents) trial, $\mathrm{P}_{2} \mathrm{Y}_{12}$ inhibitor monotherapy after 3 months of DAPT compared with prolonged DAPT resulted in significant reduction of bleeding events without an increase in major adverse cardiac and cerebrovascular events. ${ }^{49}$ In the STOPDAPT-2 (ShorT and OPtimal Duration of Dual AntiPlatelet Therapy-2) trial, clopidogrel monotherapy after 1 month of DAPT was associated with a significantly lower risk for bleeding without increasing ischemic events as compared with DAPT. ${ }^{\mathbf{5 0}}$ In TWILIGHT (Ticagrelor with Aspirin or Alone in High-Risk Patients after Coronary Intervention), ticagrelor monotherapy following 3 months of DAPT was also reported to reduce bleeding events with an equivalent ischemic risk as compared to the long duration of DAPT in high-risk patients. ${ }^{51}$ A meta-analysis of DAPT vs. monotherapy with $\mathrm{P}_{2} \mathrm{Y}_{12}$ inhibitors in patients treated with PCI showed that use of P2 $\mathrm{Y}_{12}$ monotherapy was associated with $30 \%$ lower odds of major bleeding, with similar risks for ischemic and mortality outcomes. ${ }^{\mathbf{5 2}}$ Furthermore, the HOST-EXAM (Aspirin versus clopidogrel for chronic maintenance monotherapy after percutaneous coronary intervention) trial showed that clopidogrel monotherapy as compared with aspirin monotherapy during the chronic maintenance period after PCI significantly reduced the risk of the ischemic and bleeding events. ${ }^{\mathbf{5 3}}$

\section{P2Y 12 Inhibitor Monotherapy After a Very Short Duration ofDAPT to Treat ACS}

In 2020, the TICO (Ticagrelor Monotherapy After 3 Months in the Patients Treated With New Generation Sirolimus-eluting Stent for Acute Coronary Syndrome) trial demonstrated that ticagrelor monotherapy after 3 months of DAPT compared with ticagrelor-based DAPT for 12 months significantly reduced a composite outcome of major bleeding and cardiovascular events at 1 year among patients with ACS. ${ }^{54}$ In post-hoc analysis of GLOBAL LEADERS (A Clinical Study Comparing Two Forms of Anti-platelet Therapy After Stent Implantation), ticagrelor monotherapy was associated with a lower risk of bleeding events without increasing ischemic events as compared with DAPT between 1 month and 12 months after PCI in patients with ACS. ${ }^{55,56}$ In post-hoc analysis of TWILIGHT, ticagrelor monotherapy reduced clinically meaningful bleeding events without increasing ischemic risk, as compared with ticagrelor plus aspirin among patients with or without ACS who completed an initial 3-month course of DAPT following PCI ${ }^{57}$ Pooled analysis of the SMART-DATE (Safety of 6-month Duration of Dual Antiplatelet Therapy after Acute Coronary Syndromes) and SMART-CHOICE trials showed that P2Y $Y_{12}$ inhibitor monotherapy after 3 months of DAPT reduced the risk of bleeding compared with conventional DAPT and aspirin monotherapy after 6 months of DAPT without increasing major adverse cardiac and cerebrovascular events in patients with ACS.58

Recently, the STOPDAPT-2 (ShorT and OPtimal Duration of Dual AntiPlatelet Therapy-2) ACS trial findings have been presented in the ESC 2021.59 In ACS patients, clopidogrel monotherapy after 1 month of DAPT failed to attest non-inferiority to 12 months of DAPT with aspirin and clopidogrel for the net clinical benefit, with a trend toward an increase in cardiovascular events despite substantial reduction in major bleeding events. The results of this study would be inconclusive, given the absence of a significant difference in the primary endpoint between the 2 groups. Clopidogrel monotherapy might not be the optimal antithrombotic regimen after very short duration of DAPT in patients with ACS. Therefore, further studies are warranted to define the optimal antithrombotic regimen after PCI using new generation DESs in ACS patients.

\section{Current Recommendation of DAPT Duration in the JCS Guideline}

The recommendation of DAPT duration is getting shorter due to the development of new-generation DESs, use of a $\mathrm{P} 2 \mathrm{Y}_{12}$ inhibitor as monotherapy, and the increasing prevalence of HBR patients. ${ }^{45}$ In patients with stable CAD, DAPT with prasugrel $3.75 \mathrm{mg}$ daily or clopidogrel $75 \mathrm{mg}$ daily in addition to aspirin $81-162 \mathrm{mg}$ daily is recommended for at least 1-3 months following coronary stent deployment in the JCS guideline 2020 focused update (class I) (Figure 2). Very short DAPT of 1-3 months should be considered for patients with HBR (class IIa). Monotherapy with a $\mathrm{P}_{2} \mathrm{Y}_{12}$ receptor inhibitor should be considered in patients with high thrombotic and HBR following 1-3 months of DAPT (class IIa).

In patients with ACS, prasugrel $3.75 \mathrm{mg}$ daily or clopidogrel $75 \mathrm{mg}$ daily in addition to aspirin $81-162 \mathrm{mg}$ daily is recommended for 3-12 months following coronary stent implantation (class I) (Figure 2). In patients with HBR, shortening of DAPT duration to $1-3$ months is recommended (class I). Monotherapy with a $\mathrm{P}_{2} \mathrm{Y}_{12}$ receptor inhibitor should be considered in patients with high thrombotic and HBR following short-term DAPT (class IIa).

\section{Future Perspectives}

An aspirin-free strategy is now emerging as the one of the novel strategies of antiplatelet therapy after PCI. In the ASET (Acetyl Salicylic Elimination Trial) pilot study, aspirin-free prasugrel monotherapy following successful everolimus-eluting stent implantation demonstrated feasibility and safety without any stent thrombosis in selected low-risk patients with stable CAD. ${ }^{60}$ The NEO-MINDSET (PercutaNEOus Coronary Intervention Followed by Monotherapy INstead of Dual Antiplatelet Therapy in the SETting of Acute Coronary Syndromes) trial is now ongoing and it randomizes 3,400 patients with ACS within 96h of hospital stay either to receive $\mathrm{P} 2 \mathrm{Y}_{12}$ inhibitor monotherapy or DAPT for 6 or 12 months based on the presence or absence of HBR (ClinicalTrials.gov:NCT04360720). The 
STOPDAPT-3 (ShorT and OPtimal Duration of Dual AntiPlatelet Therapy-3) trial that randomizes 3,110 patients with ACS and/or HBR before PCI either to the experimental arm of reduced-dose prasugrel monotherapy or to the control arm of DAPT is also ongoing in Japan (ClinicalTrials.gov: NCT04609111) (Figure 3). These studies might pave the way toward an aspirin-free strategy after PCI using new-generation, DESs and new-generation more potent $\mathrm{P}_{2} \mathrm{Y}_{12}$ inhibitor monotherapy.

\section{Disclosures}

T.K. is a member of Circulation Journal's Editorial Team.

\section{References}

1. Colombo A, Hall P, Nakamura S, Almagor Y, Maiello L, Martini $\mathrm{G}$, et al. Intracoronary stenting without anticoagulation accomplished with intravascular ultrasound guidance. Circulation 1995; 91: $1676-1688$.

2. Van Belle E, McFadden EP, Lablanche JM, Bauters C, Hamon $\mathrm{M}$, Bertrand ME. Two-pronged antiplatelet therapy with aspirin and ticlopidine without systemic anticoagulation: An alternative therapeutic strategy after bailout stent implantation. Coron Artery Dis 1995; 6: 341-345.

3. Schomig A, Neumann FJ, Kastrati A, Schuhlen H, Blasini R, Hadamitzky M, et al. A randomized comparison of antiplatelet and anticoagulant therapy after the placement of coronaryartery stents. N Engl J Med 1996; 334: 1084-1089.

4. Leon MB, Baim DS, Popma JJ, Gordon PC, Cutlip DE, Ho KK, et al. A clinical trial comparing three antithrombotic-drug regimens after coronary-artery stenting: Stent anticoagulation restenosis study investigators. $N$ Engl J Med 1998; 339: 1665-1671.

5. Bertrand ME, Legrand V, Boland J, Fleck E, Bonnier J, Emmanuelson H, et al. Randomized multicenter comparison of conventional anticoagulation versus antiplatelet therapy in unplanned and elective coronary stenting: The full anticoagulation versus aspirin and ticlopidine (FANTASTIC) study. Circulation 1998; 98: 1597-1603.

6. Urban P, Macaya C, Rupprecht HJ, Kiemeneij F, Emanuelsson $\mathrm{H}$, Fontanelli A, et al. Randomized evaluation of anticoagulation versus antiplatelet therapy after coronary stent implantation in high-risk patients: The multicenter aspirin and ticlopidine trial after intracoronary stenting (MATTIS). Circulation 1998; 98: 2126-2132.

7. Bertrand ME, Rupprecht HJ, Urban P, Gershlick AH. Doubleblind study of the safety of clopidogrel with and without a loading dose in combination with aspirin compared with ticlopidine in combination with aspirin after coronary stenting: The clopidogrel aspirin stent international cooperative study (CLASSICS). Circulation 2000; 102: 624-629.

8. Yusuf S, Zhao F, Mehta SR, Chrolavicius S, Tognoni G, Fox KK. Effects of clopidogrel in addition to aspirin in patients with acute coronary syndromes without ST-segment elevation. $N$ Engl J Med 2001; 345: 494-502.

9. Mehta SR, Yusuf S, Peters RJ, Bertrand ME, Lewis BS, Natarajan $\mathrm{MK}$, et al. Effects of pretreatment with clopidogrel and aspirin followed by long-term therapy in patients undergoing percutaneous coronary intervention: The PCI-CURE study. Lancet 2001; 358: $527-533$.

10. Steinhubl SR, Berger PB, Mann JT 3rd, Fry ET, DeLago A, Wilmer C, et al. Early and sustained dual oral antiplatelet therapy following percutaneous coronary intervention: A randomized controlled trial. JAMA 2002; 288: 2411-2420.

11. Moses JW, Leon MB, Popma JJ, Fitzgerald PJ, Holmes DR, O'Shaughnessy C, et al. Sirolimus-eluting stents versus standard stents in patients with stenosis in a native coronary artery. $N$ Engl J Med 2003; 349: 1315-1323.

12. Kimura T, Morimoto T, Nakagawa Y, Kawai K, Miyazaki S, Muramatsu T, et al. Very late stent thrombosis and late target lesion revascularization after sirolimus-eluting stent implantation: Five-year outcome of the j-Cypher registry. Circulation 2012; 125: 584-591.

13. Serruys PW. FDA panel, 7 and 8 December 2006: The impact on our practice and research. EuroIntervention 2007; 2: 405-407.

14. Pfisterer M, Brunner-La Rocca HP, Buser PT, Rickenbacher P, Hunziker P, Mueller C, et al. Late clinical events after clopidogrel discontinuation may limit the benefit of drug-eluting stents:
An observational study of drug-eluting versus bare-metal stents. J Am Coll Cardiol 2006; 48: 2584-2591.

15. Eisenstein EL, Anstrom KJ, Kong DF, Shaw LK, Tuttle RH, Mark DB, et al. Clopidogrel use and long-term clinical outcomes after drug-eluting stent implantation. JAMA 2007; 297: 159-168.

16. Daemen J, Wenaweser P, Tsuchida K, Abrecht L, Vaina S, Morger C, et al. Early and late coronary stent thrombosis of sirolimus-eluting and paclitaxel-eluting stents in routine clinical practice: Data from a large two-institutional cohort study. Lancet 2007; 369: 667-678.

17. Levine GN, Bates ER, Blankenship JC, Bailey SR, Bittl JA, Cercek B, et al. 2011 ACCF/AHA/SCAI guideline for percutaneous coronary intervention: A report of the American College of Cardiology Foundation/American Heart Association task force on practice guidelines and the society for cardiovascular angiography and interventions. Circulation 2011; 124: e574-e651.

18. Wijns W, Kolh P, Danchin N, Di Mario C, Falk V, Folliguet T, et al. Guidelines on myocardial revascularization. Eur Heart $J$ 2010; 31: 2501-2555.

19. Wiviott SD, Braunwald E, McCabe CH, Montalescot G, Ruzyllo $\mathrm{W}$, Gottlieb S, et al. Prasugrel versus clopidogrel in patients with acute coronary syndromes. N Engl J Med 2007; 357: 2001-2015.

20. Wallentin L, Becker RC, Budaj A, Cannon CP, Emanuelsson H, Held C, et al. Ticagrelor versus clopidogrel in patients with acute coronary syndromes. N Engl J Med 2009; 361: 1045-1057.

21. Palmerini T, Biondi-Zoccai G, Della Riva D, Stettler C, Sangiorgi D, D'Ascenzo F, et al. Stent thrombosis with drug-eluting and bare-metal stents: Evidence from a comprehensive network meta-analysis. Lancet 2012; 379: 1393-1402.

22. Valgimigli M, Campo G, Monti M, Vranckx P, Percoco G, Tumscitz C, et al. Short- versus long-term duration of dualantiplatelet therapy after coronary stenting: A randomized multicenter trial. Circulation 2012; 125: 2015-2026.

23. Mauri L, Kereiakes DJ, Yeh RW, Driscoll-Shempp P, Cutlip DE, Steg PG, et al. Twelve or 30 months of dual antiplatelet therapy after drug-eluting stents. N Engl J Med 2014; 371: 2155 2166.

24. Lee CW, Ahn JM, Park DW, Kang SJ, Lee SW, Kim YH, et al. Optimal duration of dual antiplatelet therapy after drug-eluting stent implantation: A randomized, controlled trial. Circulation 2014; 129: 304-312.

25. Collet JP, Silvain J, Barthelemy O, Range G, Cayla G, Van Belle $\mathrm{E}$, et al. Dual-antiplatelet treatment beyond 1 year after drugeluting stent implantation (ARCTIC-Interruption): A randomised trial. Lancet 2014; 384: 1577-1585.

26. Gilard M, Barragan P, Noryani AAL, Noor HA, Majwal T, Hovasse T, et al. 6- versus 24-month dual antiplatelet therapy after implantation of drug-eluting stents in patients nonresistant to aspirin: The randomized, multicenter ITALIC Trial. $J \mathrm{Am}$ Coll Cardiol 2015; 65: 777-786.

27. Helft G, Steg PG, Le Feuvre C, Georges JL, Carrie D, Dreyfus $\mathrm{X}$, et al. Stopping or continuing clopidogrel 12 months after drug-eluting stent placement: The OPTIDUAL randomized trial. Eur Heart J 2016; 37: 365-374.

28. Gwon HC, Hahn JY, Park KW, Song YB, Chae IH, Lim DS, et al. Six-month versus 12-month dual antiplatelet therapy after implantation of drug-eluting stents: The efficacy of xience/promus versus cypher to reduce late loss after stenting (EXCELLENT) randomized, multicenter study. Circulation 2012; 125: 505-513.

29. Kim BK, Hong MK, Shin DH, Nam CM, Kim JS, Ko YG, et al. A new strategy for discontinuation of dual antiplatelet therapy: The RESET trial (REal Safety and Efficacy of 3-month dual antiplatelet Therapy following endeavor zotarolimus-eluting stent implantation). J Am Coll Cardiol 2012; 60: 1340-1348.

30. Feres F, Costa RA, Abizaid A, Leon MB, Marin-Neto JA, Botelho RV, et al. Three vs twelve months of dual antiplatelet therapy after zotarolimus-eluting stents: The OPTIMIZE randomized trial. JAMA 2013; 310: 2510-2522.

31. Colombo A, Chieffo A, Frasheri A, Garbo R, Masotti-Centol $\mathrm{M}$, Salvatella N, et al. Second-generation drug-eluting stent implantation followed by 6 - versus 12 -month dual antiplatelet therapy: The SECURITY randomized clinical trial. $J$ Am Coll Cardiol 2014; 64: 2086-2097.

32. Schulz-Schupke S, Byrne RA, Ten Berg JM, Neumann FJ, Han Y, Adriaenssens T, et al. ISAR-SAFE: A randomized, double-blind, placebo-controlled trial of 6 vs. 12 months of clopidogrel therapy after drug-eluting stenting. Eur Heart $J$ 2015; 36: 1252-1263.

33. Han Y, Xu B, Xu K, Guan C, Jing Q, Zheng Q, et al. Six versus 12 months of dual antiplatelet therapy after implantation of biodegradable polymer sirolimus-eluting stent: Randomized sub- 
study of the I-LOVE-IT 2 trial. Circ Cardiovasc Interv 2016; 9: $\mathrm{e} 003145$.

34. Nakamura M, Iijima R, Ako J, Shinke T, Okada H, Ito Y, et al. Dual antiplatelet therapy for 6 versus 18 months after biodegradable polymer drug-eluting stent implantation. JACC Cardiovasc Interv 2017; 10: 1189-1198.

35. Palmerini T, Sangiorgi D, Valgimigli M, Biondi-Zoccai G, Feres F, Abizaid A, et al. Short- versus long-term dual antiplatelet therapy after drug-eluting stent implantation: An individual patient data pairwise and network meta-analysis. $\mathrm{J} \mathrm{Am} \mathrm{Coll}$ Cardiol 2015; 65: 1092-1102.

36. Palmerini T, Benedetto U, Bacchi-Reggiani L, Della Riva D, Biondi-Zoccai G, Feres F, et al. Mortality in patients treated with extended duration dual antiplatelet therapy after drugeluting stent implantation: A pairwise and bayesian network meta-analysis of randomised trials. Lancet 2015; 385: 2371-2382.

37. Giustino G, Baber U, Sartori S, Mehran R, Mastoris I, Kini AS, et al. Duration of dual antiplatelet therapy after drug-eluting stent implantation: A systematic review and meta-analysis of randomized controlled trials. J Am Coll Cardiol 2015; 65: 1298-1310.

38. Toyota T, Shiomi H, Morimoto T, Natsuaki M, Kimura T. Short versus prolonged dual antiplatelet therapy (DAPT) duration after coronary stent implantation: A comparison between the DAPT study and 9 other trials evaluating DAPT duration. PLoS One 2017; 12: $\mathrm{e} 0174502$.

39. Levine GN, Bates ER, Bittl JA, Brindis RG, Fihn SD, Fleisher LA, et al. 2016 ACC/AHA guideline focused update on duration of dual antiplatelet therapy in patients with coronary artery disease: A report of the American College of Cardiology/American Heart Association task force on clinical practice guidelines. Circulation 2016; 134: e123-e155.

40. Urban P, Meredith IT, Abizaid A, Pocock SJ, Carrie D, Naber $\mathrm{C}$, et al. Polymer-free drug-coated coronary stents in patients at high bleeding risk. $N$ Engl J Med 2015; 373: 2038-2047.

41. Costa F, van Klaveren D, James S, Heg D, Raber L, Feres F, et al. Derivation and validation of the predicting bleeding complications in patients undergoing stent implantation and subsequent dual antiplatelet therapy (PRECISE-DAPT) score: A pooled analysis of individual-patient datasets from clinical trials. Lancet 2017; 389: $1025-1034$.

42. Valgimigli M, Bueno H, Byrne RA, Collet JP, Costa F, Jeppsson A, et al. 2017 ECS focused update on dual antiplatelet therapy in coronary artery disease developed in collaboration with EACTS: The task force for dual antiplatelet therapy in coronary artery disease of the European Society of Cardiology (ESC) and of the European Association for Cardio-Thoracic Surgery (EACTS). Eur Heart J 2018; 39: 213-260.

43. Natsuaki M, Morimoto T, Yamaji K, Watanabe H, Yoshikawa $\mathrm{Y}$, Shiomi H, et al. Prediction of thrombotic and bleeding events after percutaneous coronary intervention: CREDO-Kyoto thrombotic and bleeding risk scores. $J$ Am Heart Assoc 2018; 7: e008708.

44. Urban P, Mehran R, Colleran R, Angiolillo DJ, Byrne RA, Capodanno $\mathrm{D}$, et al. Defining high bleeding risk in patients undergoing percutaneous coronary intervention. Circulation 2019; 140: $240-261$

45. Nakamura M, Kimura K, Kimura T, Ishihara M, Otsuka F, Kozuma K, et al. JCS 2020 guideline focused update on antithrombotic therapy in patients with coronary artery disease. Circ J 2020; 84: $831-865$.

46. Windecker S, Latib A, Kedhi E, Kirtane AJ, Kandzari DE, Mehran R, et al. Polymer-based or polymer-free stents in patients at high bleeding risk. N Engl J Med 2020; 382: 1208-1218.

47. Hankey GJ, Sudlow CL, Dunbabin DW. Thienopyridines or aspirin to prevent stroke and other serious vascular events in patients at high risk of vascular disease?: A systematic review of the evidence from randomized trials. Stroke 2000; 31: 1779-1784.

48. Chiarito M, Sanz-Sanchez J, Cannata F, Cao D, Sturla M, Panico C, et al. Monotherapy with a P2Y12 inhibitor or aspirin for secondary prevention in patients with established atherosclerosis: A systematic review and meta-analysis. Lancet 2020; 395: $1487-1495$.

49. Hahn JY, Song YB, Oh JH, Chun WJ, Park YH, Jang WJ, et al. Effect of P2Y12 inhibitor monotherapy vs dual antiplatelet therapy on cardiovascular events in patients undergoing percutaneous coronary intervention: The SMART-CHOICE randomized clinical trial. JAMA 2019; 321: 2428-2437.

50. Watanabe H, Domei T, Morimoto T, Natsuaki M, Shiomi H, Toyota T, et al. Effect of 1-month dual antiplatelet therapy followed by clopidogrel vs 12-month dual antiplatelet therapy on cardiovascular and bleeding events in patients receiving PCI: The STOPDAPT-2 randomized clinical trial. JAMA 2019; 321: $2414-2427$.

51. Mehran R, Baber U, Sharma SK, Cohen DJ, Angiolillo DJ, Briguori $C$, et al. Ticagrelor with or without aspirin in high-risk patients after PCI. $N$ Engl J Med 2019; 381: 2032-2042.

52. Malik AH, Yandrapalli S, Shetty SS, Aronow WS, Cooper HA, Panza JA. Meta-analysis of dual antiplatelet therapy versus monotherapy with P2Y12 inhibitors in patients after percutaneous coronary intervention. Am J Cardiol 2020; 127: 25-29.

53. Koo BK, Kang J, Park KW, Rhee TM, Yang HM, Won KB, et al. Aspirin versus clopidogrel for chronic maintenance monotherapy after percutaneous coronary intervention (HOST-EXAM): An investigator-initiated, prospective, randomised, open-label, multicentre trial. Lancet 2021; 397: 2487-2496.

54. Kim BK, Hong SJ, Cho YH, Yun KH, Kim YH, Suh Y, et al. Effect of ticagrelor monotherapy vs ticagrelor with aspirin on major bleeding and cardiovascular events in patients with acute coronary syndrome: The TICO randomized clinical trial. JAMA 2020; 323: 2407-2416.

55. Vranckx P, Valgimigli M, Juni P, Hamm C, Steg PG, Heg D, et al. Ticagrelor plus aspirin for 1 month, followed by ticagrelor monotherapy for 23 months vs aspirin plus clopidogrel or ticagrelor for 12 months, followed by aspirin monotherapy for 12 months after implantation of a drug-eluting stent: A multicentre, open-label, randomised superiority trial. Lancet 2018; 392: 940-949.

56. Tomaniak M, Chichareon P, Onuma Y, Deliargyris EN, Takahashi $\mathrm{K}$, Kogame N, et al. Benefit and risks of aspirin in addition to ticagrelor in acute coronary syndromes: A post hoc analysis of the randomized GLOBAL LEADERS trial. JAMA Cardiol 2019; 4: 1092-1101.

57. Baber U, Dangas G, Angiolillo DJ, Cohen DJ, Sharma SK, Nicolas J, et al. Ticagrelor alone vs. Ticagrelor plus aspirin following percutaneous coronary intervention in patients with nonST-segment elevation acute coronary syndromes: TWILIGHT-ACS. Eur Heart J 2020; 41: 3533-3545.

58. Song PS, Park YH, Oh JH, Song YB, Choi SH, Gwon HC, et al. P2Y12 inhibitor monotherapy versus conventional dual antiplatelet therapy or aspirin monotherapy in acute coronary syndrome: A pooled analysis of the SMART-DATE and SMART-CHOICE trials. Am J Cardiol 2021; 150: 47-54

59. Watanabe H. STOPDAPT-2 ACS: One-month dual antiplatelet therapy followed by clopidogrel monotherapy in acute coronary syndrome. European Society of Cardiology 2021; Hot Line Session.

60. Kogame N, Guimaraes PO, Modolo R, De Martino F, Tinoco J, Ribeiro EE, et al. Aspirin-free prasugrel monotherapy following coronary artery stenting in patients with stable cad: The ASET pilot study. JACC Cardiovasc Interv 2020; 13: 2251-2262. 